which was with difficulty excluded from the interior of houses. Their duration varied from a few hours to two days; and from the fact that one of the dust-winds was simultareously experienced at Hankow, Kiukiang, and Chinkiang-a portion of the river's course nearly equal to 450 miles-I may conclude that they were not local phenomena, but possessed a considerable horizontal extension. The dust, which in all respects resembles the loam forming the banks and alluvial plains of the Yang-tse, is composed of mineral particles and vegetable débris - the former varying from $\frac{1}{\partial \sigma} \gamma$ to $\frac{1}{10 \sigma 0}$ of an inch in size, and being generally siliceous or calcareous in composition.

Three dust-winds came under my observation on March 25, April 2I, and May I; all of them possessed the following meteorological conditions:-During the two or three preceding days the barometer fell, whilst the mean daily temperature rose, and in two instances the winds were light and southerly. During the continuance of the dust-winds the barometer rose, the mean daily temperature ceased to rise, and light winds with a force of $I$ and 2 prevailed varying in direction from north to north-east. For a period of a day or two after the dust-winds had ceased the thermometer registered a lower mean daily tem perature, the barometer continued to rise, and the wind retained the same northerly direction. In all three cases there was a disturked electrical condition of the atmosphere: in the first instance a severe thunderstorm accompanied by heavy rain occurred on the day following; the second dust.wind was accompanied at its commencement by a little thunder and lightning, but by no rain; whilst during the two days preceding the third dust-wind there was a considerable amount of thunder and lightning, together with heavy rain.

From this comparison of the prevailing atmospheric conditions in connection $w$ ith these dust-winds, a more probable explanation of their occurrence may be obtained, than that which is often proposed when simply assigning a "sudden breeze" and a "hot day" as the conditions required to give rise to them.

I7, Wood Lane, Falmouth, June I

H. B. GUPPY

\section{A Singular Cause of Shipwreck}

THE strange lois of the Phanix off the Iceland coast may perhaps lend some interest to the following :-

Last summer was the best the Icelanders had had for long past. I regret that I can give no thermometric readings, as my instrument became useless during the voyage. The weather in the north was nearly as warm as it has been here lately. All the snow-fed rivers were very full. The Jökuls à was nearly up to its high water-mark quite early in the season, and the Blanda was almost impassable. Icelanders who rode with me said that they had never seen the mountains from Hof's Jökul to Eyrik's Jökul so free from snow.

I append extracts from a letter which $I$ have just received from one of my guides.

St. Thomas's Hospital, S.E, June 4

A. J. Hubbard

(Verbatim copy)

" Hjedinstrofda, April 16, I881

". . This winter has been so uncommonly strong that none such has existed this century. The frost has been extremely severe $-32^{\circ} \mathrm{R}$, once at Akurtyri, and $36^{\circ} \mathrm{R} .\left(=49 \frac{1}{2}^{\circ} \mathrm{Fahh}\right.$. $)$ somewhere with Myvatn. . . . Ptarmigans and other birds froze to deatb. The farmers had spent most of their hay, and their cattle were to be killed or starve to death. All the sea was covered with ice, mostly polar ice, as far as one could see from the tops of the mountains. On the 2nd inst. the weather was mild, and on the 7 th we had a real thaw, and every day since very mild and fine weather. But - it is possible that the ice will not drive aw ay before late in August, and no ship can come to any harbour on the northern coast ; this happened in 1869. "KRISTJAN JónASARSON"

\section{An Optical Illusion}

THE optical illusion described in NATURE, vol, xxiv. p. 54, is, as I have already mentioned, referred to by Priestley (History, \&c., Vision, Light, and Colours, vol. ii. p. 725). The description is as follows:-" M. Le Cat well explains a remarkable deception by which a person shall imagine an object to be on the opposite side of a board when it is not so, and also inverted and magnified. It is illustrated by Fig. $I 62$, in which $D$ repre- sents the eye and С в a large black board pierced with a small hole, $\mathbf{E}$ is a large white board placed beyond it, and strongly illuminated, and $d$ a pin or other small object held betwixt the eye and the first board. In these circumstances the pin shall be imagined to be at $\mathrm{F}$ on the other side of the board, where it will appear inverted and magnified, because what is in fact perceived is the shadow of the pin upon the retina; and the light that is stopped by the upper part of the pin, coming from the lower part of the enlightened board, and that which is stopped by the lower part coming from the upper part of the board, the shadow must necessarily be inverted with respect to the object." ("Traité des Sens," par M. Le Cat, Amsterdam, 1744, p. 298.)

C. J. WOODWARD

Birmingham and Midland Institute, Birmingham, June 6

\section{THE VISITATION OF THE ROYAL OBSERVATORY}

THE Report of the Astronomer-Royal to the Board of Visitors on Saturday last at the annual visitation was listened to with special interest, and indeed the attendance of astronomers and others at the observatory was very much larger than usual, because it was generally understood that this would be the last occasion of the kind on which the veteran astronomer would be seen at his post. We learn that an appropriate address was made to him by the Board of Visitors when he announced his attention of relinquishing his official duties in order to enable him to devote all his time and energies to the researches he has now on hand.

The astronomical observations, which occupy the first part of the Report, have been carried on with the usual diligence. Most of the routine work of the Observatory seems to have gone on in the usual fashion through the last year.

One of the objects of interest on this occasion was Halley's ancient tombstone, which, after its removal from Lee Churchyard (where it had been replaced by a new stone with a facsimile of the inscription), had been placed in the South Ground, where it had been lying for several years. It has now been carefully restored, and mounted on the east wall of the lobby of the North Dome.

'The sun's chromosphere has been examined with the half-prism spectroscope on 29 days during the period to which this report refers. Fourteen sun-spots have been examined on 20 days, with reference to the broadening of the lines in their spectra. The results confirm the remark that some of the lines of iron are broadened in some spots, whilst others are broadened in other spots. Displacements of some of the lines of iron towards the red, and of others towards the blue, have also been noted in the case of one spot. A remarkable spectrum of a sun-spot showing I7 strong black lines or bands, each as broad as $b_{1}$, in the solar spectrum, was observed on November 27 and 29,1880 . These bands, to which there is nothing corresponding in the solar spectrum (except some very faint lines), have also been subsequently remarked in the spectra of several spots.

For the determination of motions of stars in the line of sight, 168 measures have been made of the displacement of the $F$ line in the spectra of 43 stars, 87 of the $b_{1}$ line in 27 stars, and 8 of the $b_{4}$ line in 4 of these stars. Of these 70 stars 16 had not previously been examined, and the total number of stars of which the motions have been spectroscopically determined is now 91. In the case of 6 of the stars observed in the last year, a disfersive power equivalent to that given by 16 prisms of $60^{\circ}$ has been used. Ten measures have been made of the relative displacement of the $F$ and $b$ lines in the spectra of the east and west limbs of Jupiter.

Comet I8I0 $d$ (Hartwig's), and the aurora of I88I, January $3 \mathrm{I}$, have been spectroscopically examined.

Between 1880, May 9, and I88r, May I3, photographs of the sun were taken on 140 days, and of these 284 have been selected for preservation. There are only 8 days 